\title{
Artelogie
}

artelogie Recherche sur les arts, le patrimoine et la littérature de l'Amérique latine

14 | 2019

Sensibilités : Arts, littératures et patrimoine en Amérique latine

\section{Sobre o lugar das sensibilidades e emoções na produção do pensamento}

\section{Antonio Herculano Lopes}

\section{(2) OpenEdition \\ 1 Journals}

Edição electrónica

URL: http://journals.openedition.org/artelogie/3800

DOI: $10.4000 /$ artelogie.3800

ISSN: 2115-6395

Editora

Association ESCAL

Refêrencia eletrónica

Antonio Herculano Lopes, « Sobre o lugar das sensibilidades e emoções na produção do pensamento », Artelogie [Online], 14 | 2019, posto online no dia 17 setembro 2019, consultado o 17 setembro 2019. URL : http://journals.openedition.org/artelogie/3800; DOI : 10.4000/artelogie.3800

Este documento foi criado de forma automática no dia 17 Setembro 2019.

Association ESCAL 


\title{
Sobre o lugar das sensibilidades e emoções na produção do pensamento
}

\author{
Antonio Herculano Lopes
}

1 Sobre o lugar das sensibilidades e emoções na produção do pensamento

El sueño de la razón produce monstruos

$(\text { Goya })^{1}$

Licht, mehr Licht!

(Goethe $)^{2}$

2 Maio de 1968, Paris, as ruas em conflito aberto, caos, violência e slogans. Entre os mais conhecidos, "A imaginação no poder". Por entre as barricadas, caminha um grupo muito particular: Herbert Marcuse, já então muito conhecido por seu livro Eros e civilização, Lucien Goldmann, autor de Por uma sociologia do romance, e um jovem orientando seu, Jacques Leenhardt. Trata-se da ponta de lança de um marxismo revisitado, que condena tanto o capitalismo como o socialismo soviético. Chocado com o que vê, o filósofo alemão comenta: - Eles não entenderam nada... Ao que o romeno Goldmann replica: - Mas, Herbert, eles estão aqui por sua causa! ${ }^{3}$

3 Talvez, aquele que propunha a Grande Recusa não aceitasse que suas ideias estivessem sendo honradas pelos estudantes franceses sublevados, em função da violência e da manifestação de irracionalidade ali presentes, enquanto Marcuse justamente denunciava o irracionalismo da sociedade capitalista, disfarçado sob uma racionalidade técnica e uma ciência enclausurada pela positividade. Talvez a Escola de Frankfurt, a que ele se filiava, tenha sido a última grande expressão do pensamento ocidental a tentar resgatar os valores centrais do Iluminismo, ao propugnar, contra uma razão instrumental, uma razão crítica e dialética. 
Mais ou menos concomitante aos acontecimentos de Paris, os estudantes brasileiros se sublevavam contra os desmandos da ditadura militar e também transformavam em praça de guerra as ruas do Rio de Janeiro e de outras cidades do país. Na Passeata dos Cem Mil, em junho daquele ano emblemático, as faixas demandavam "O povo no poder". Não que algo semelhante não ocorresse em Paris, onde "le pouvoir populaire" era também uma palavra de ordem. Tampouco é certo que no Brasil o manifesto em prol da imaginação não tivesse sua contraparte, ainda que mais na arte do que na política. Por aqui, em 1967, o movimento tropicalista se anunciava ruidosamente na música popular, com Alegria, alegria, de Caetano Veloso, e no teatro, com 0 rei da vela, de Oswald de Andrade, dirigido por José Celso Martinez Correia.

O fato é que se os contextos políticos eram bastante distintos, na cultura - sobretudo numa cultura jovem circulada pela mesma indústria cultural condenada pelos frankfurtianos - a negatividade e a radicalidade se expressavam por toda parte, marcadas com frequência por uma forte desconfiança do intelectualismo e por uma celebração seja da ação (inclusive pela violência), seja do prazer (com a cultura das drogas, do corpo e do sexo livre) ou mesmo de ambos conjugados, como no caso dos estudantes franceses. No Brasil, em que o aprofundamento da ditadura militar se deu no final de 1968, a juventude universitária radical entrou nos anos 1970 se dividindo entre a ação armada e o desbunde. Lá e cá, nenhum desses movimentos obteve sucesso em seus objetivos declarados, mas a atenção a uma história subterrânea, como costumam ser os movimentos da cultura, nos permite detectar ainda hoje os impactos daquelas ondas de emoção explosiva nas sensibilidades e nas percepções passados 50 anos.

6 Recuemos um século, para o ano igualmente emblemático das revoltas do século XIX, 1848, quando podemos imaginar Marx, também nas barricadas de Paris, se inspirando para desenvolver seu programa radical de superação do capitalismo, enquanto defensor da unidade de pensamento e ação. Arriscando-me a chover no molhado, vou retomar alguns pontos de sua reflexão, que lançam as bases para o surgimento das ciências sociais. Vindo da filosofia e, em particular, da esquerda hegeliana, seu primeiro movimento precisava ser o da crítica às próprias bases do pensamento filosófico ocidental, que, na linha que vem do mundo das ideias, de Platão, ao cogito descartiano, compreende o mundo concreto como uma expressão do ideal. De Hegel, no entanto, em que o idealismo atinge seu cume - consagrado na fórmula o que é real é racional e o que é racional é real (HEGEL, 1997: p. 36) -, Marx guardará o pensamento dialético, começando sua crítica por uma inversão de perspectiva, em que o materialismo de Feuerbach lhe permitiu botar Hegel, que estava "de cabeça para baixo", de pés no chão. Em seguida, voltou-se para a teoria política francesa e a teoria econômica inglesa para refinar sua análise social. 0 resultado aparece em sua formulação clássica de 1859, no Prefácio à Contribuição à crítica à economia política, que sintetiza sua teoria da história e da sociedade: 0 modo de produção da vida material condiciona o processo da vida social, política e intelectual em geral. Não é a consciência dos homens que determina o seu ser; mas inversamente é o seu ser social que determina a sua consciência (MARX, 1972: p. 4). ${ }^{4}$

7 Enquanto em Hegel o movimento da história se apresentava como uma circularidade em progresso, em que por sucessivas superações (Aufhebungen) o Espírito se revela em sua plenitude, Marx também pensa numa história progressiva em que a sociedade caminha para a sua forma mais perfeita, o comunismo. Não é o racional que constitui o real ao apreender sua verdade; mas é o real, isto é, a vida dos seres humanos em sociedade, que 
permite à razão apreender a verdade do ser em si e para si. Nessa inversão materialista, Marx se afasta da filosofia e abre o caminho para uma ciência da sociedade.

8 A resolução do problema da relação entre ser e consciência é talvez a questão mais espinhosa desse caminho, que se aparta das ciências exatas e da natureza e remete ao das formas de percepção do mundo, incluindo os sentidos, as emoções e sensibilidades e a razão. Esta última reina absoluta no século XIX enquanto dimensão da superioridade da espécie humana e por ela os seres humanos seriam capazes de entender sua condição contraditória e seus interesses (conflitantes numa sociedade de classes) e agir na direção do progresso social, seja pelo desenvolvimento das forças produtivas, seja pelos momentos de ruptura e revolução. Nesse sentido, os sentidos, as emoções e as sensibilidades enquanto outras formas de apreensão do real não são ignorados, mas ficam submetidos à razão libertadora. Somente numa sociedade plenamente racional poderão os seres humanos usufruir plenamente de suas capacidades sensíveis, libertados do reino do trabalho e podendo se dedicar às artes e as assim chamadas "questões do espírito".

Marx procurou resolver o problema da relação ser-consciência por meio do pensamento dialético, que ao mesmo tempo lhe permitiu estabelecer uma relação de determinação e manter uma dinâmica contraditória entre os polos. No mesmo prefácio, pouco adiante, parece apontar para as dificuldades do método científico no trato das questões do espírito. Ao falar das épocas de revolução social, assim trata dos processos de mudança: [É] preciso distinguir sempre entre as profundas transformações materiais, constatáveis de maneira cientificamente rigorosa, das condições de produção econômicas $e$ as formas jurídicas, políticas, religiosas, artísticas ou filosóficas, em suma, as formas ideológicas sob as quais os homens tomam consciência desse conflito e o levam a cabo (MARX, 1972: p.4-5). O mundo da economia pode ser objeto de estudo científico rigoroso, enquanto o da consciência, pela qual os homens agem em sociedade, deve ser deduzido ou interpretado a partir do primeiro.

Essa dificuldade epistemológica vai acompanhar e assombrar o marxismo e, na virada para o século XX, quando a profunda crença na razão começa a ser abalada, começa a produzir outras respostas em distintas teorias sociais, como a das afinidades eletivas em Weber, a sociologia da religião em Durkheim ou a dádiva em Mauss. Se, como diz Marx, não se pode julgar uma tal época de mudanças pela consciência que ela tem de si (MARX, 1972: p. 5), tampouco se pode entendê-la sem levar em conta a forma como ela se autorrepresentou. E mais, para tanto não basta a consciência racional dos indivíduos movidos por seus interesses da economia política clássica, mas é preciso entender os valores que os embasam, os medos, os desejos, as contradições, os afetos e as paixões, que com frequência suplantam a ação racional.

11 O abalo no reinado da Razão vai dar margem ao surgimento de pensadores sociais e historiadores como Georg Simmel e Johan Huizinga, com quem as questões da consciência e das sensibilidades não são tratadas como derivadas, mas como constitutivas da vida social. Na sua discussão sobre o conceito de cultura subjetiva, Simmel aponta para uma qualidade intrínseca à espécie humana - a da perfectibilidade do espírito, processo que se dá por meio de uma intervenção teleológica, isto é, fruto de uma vontade e de uma intenção (SIMMEL, 1971: p. 227-234). Esse projeto de perfectibilidade, ou dito de outra forma de cultivo, de criação de uma cultura, é um processo ao mesmo tempo individual e coletivo em busca de uma ideia de perfeição (de volta a Platão), que talvez pudesse ser resumida pela tríplice aspiração do Ocidente moderno: liberdade, igualdade e fraternidade. $\mathrm{O}$ desenvolvimento das sociedades industriais contemporâneas, no entanto, assistiu à crescente autonomização de uma cultura objetiva em expansão (a proliferação 
dos objetos por meio dos quais o cultivo se torna possível), sem correspondência no adensamento da cultura subjetiva (em última análise, o aperfeiçoamento do espírito como resultado esperado da cultura). Essa dissociação entre cultura objetiva e subjetiva seria uma síndrome da modernidade.

Simmel nos dá uma pista para compreender melhor tal síndrome (o termo não é dele) ao comparar as formas pelas quais os habitantes das metrópoles diferem daqueles de vilarejos e campos na percepção da realidade social. Ele se refere ao caráter intelectualista da vida anímica do habitante da cidade grande, frente ao habitante da cidade pequena, que é antes baseado no ânimo e nas relações pautadas pelo sentimento. Pois estas lançam raízes nas camadas mais inconscientes da alma e crescem sobretudo na calma proporção de hábitos ininterruptos. Em contraposição a isto, o lugar do entendimento são as camadas mais superiores, conscientes $e$ transparentes de nossa alma [...] (SIMMEL, 2005: p. 578). O lugar do entendimento em oposição ao sentimento: não que Simmel presuma que as populações pré-industriais não pautavam suas ações também pelo entendimento, mas algo se rompeu na nova ordem criada pelas grandes cidades.

O século conhecerá ainda muitos outros finos analistas que seguem o mesmo caminho, como Walter Benjamin e Norbert Elias ou os historiadores Lucien Febvre e Philippe Ariès, mas é só com o enorme impacto dos acontecimentos de 1968 que se torna mais sistemático um esforço de ir além das polaridades corpo e mente, ser e consciência ou sociedade e cultura. Barthes, Derrida, Foucault e o chamado pós-estruturalismo francês se tornam um marco importante nessa trajetória, assim como as contribuições da linguística, da crítica literária e dos estudos culturais. Áreas disciplinares que não são novas ganham maior densidade e importância, como a sociologia da cultura, a antropologia das emoções ou a história cultural, que recebe o epíteto de "nova". Uma história das sensibilidades, que já havia sido preconizada por Febvre, começa a ganhar mais densidade, com destaque para a obra de Alain Corbin. Os temas de pesquisa se multiplicam para buscar entender todas as interfaces com o mundo que nos fazem humanos: sons, cheiros, paladar, percepções do corpo, sexualidade, o vasto complexo das emoções e o inefável domínio das sensibilidades. As dificuldades que tais questões colocam para a pesquisa histórica e sociológica são imensas, mas se apresentam como inevitáveis. Entre nós, é a obra de Sandra Jatahy Pesavento que mais diretamente aponta para a necessidade de uma história das sensibilidades, como parte de um projeto mais amplo da história cultural, preocupada com as representações que as diferentes sociedades humanas constroem a respeito de si.

Se olharmos retrospectivamente para o Brasil, ao longo de todo o período que coincide com sua história enquanto nação independente, podemos perceber a dificuldade do intelectual oitocentista em pensar no conjunto de uma sociedade marcada por uma violência estrutural, a escravidão, que limitava a percepção de um "nós" à parte livre do corpo social. O conceito romântico de nação, que incluía um povo, uma língua, uma cultura não se coadunava com a mistura de povos, línguas e culturas existente e reforçava os laços de pertencimento transatlântico. Essa dupla pertença identitária era um sentimento de não-contradição entre um ser brasileiro e um ser ocidental.

As gerações de intelectuais e artistas posteriores à Independência buscaram com frequência construir a ideia de nação contra o antigo colonizador, mas não contra a Europa, de quem eles se sentiam culturalmente caudatários. Em sua percepção, éramos o Extremo Ocidente, a América, onde uma nova civilização se formava a partir do Velho 
Mundo, e não contra ele. Negros e índios eram o verdadeiro Outro daquela sociedade, no dizer de Flávio Aguiar (AGUIAR, 1984: p. 13), um "outro interno". 5

o fato de nos tornarmos independentes mantendo o modelo monárquico europeu, ainda que em sua vertente reformada, reforçou no Brasil em particular esse sentimento de continuidade. Com o tempo, mesmo o português, tendo perdido seu potencial de ameaça, pôde ser reincorporado ao trio constituidor da nacionalidade, com a necessária liderança do elemento europeu, portador de civilização e destinado a redimir africanos e indígenas da barbárie. Assim, quando Joaquim Nabuco (NABUCO, 1974: p.59) diz, em Minha formação, que o sentimento em nós é brasileiro, a imaginação europeia, ele está se referindo a algo bem mais delicado e profundo, palavras que utiliza, do que seus críticos costumam ver.

A ambiguidade estrutural decorre, em parte, dessa dificuldade de se definir um fundamento próprio para a nação. 0 "povo" do Romantismo não poderia sê-lo. Numa sociedade escravocrata, com vastas populações pobres e livres, em que predominava a mestiçagem, seria difícil dar ao povo o protagonismo. A imaginação de nossos intelectuais e artistas era liberal, o sentimento aristocrático. Numa sociedade recém-saída de séculos de um patriarcalismo rígido, a imaginação podia ser democrática e burguesa, o sentimento ainda era fortemente pautado pela hierarquia e pela autoridade do pater familias. Numa sociedade gestada no Velho Regime, a imaginação podia se deixar arrebatar pela utopia americana, o sentimento era fortemente conservador e cauteloso.

José de Alencar pensou o país nessa chave, mas foi mais além de seus contemporâneos ao representar o negro nos palcos fluminenses com um grau de centralidade raro para a época, em $O$ demônio familiar, em que o moleque Pedro, ainda não sendo o personagem central, é o condutor da trama em seu papel arlequinesco. Claro que a Pedro não é oferecida uma perspectiva de redenção de sua condição, a não ser que aprenda a se elevar em honra e cultura ao nível do homem branco, seu superior. Da mesma forma, Alencar, em As asas de um anjo, ousa na representação de Carolina, uma mulher tida como caída, pela infidelidade conjugal, mas que se apresenta forte e digna em sua defesa enquanto uma injustiçada pela moral masculina, que ao homem tudo permite. Ainda assim, o autor não deixa de castigá-la. 0 mais importante, no entanto, é que ele lidou, por meio de uma linguagem de forte impacto social como o teatro, com dois dos grandes fantasmas daquela sociedade patriarcal e escravista.

Uma mudança mais profunda na autopercepção daquela sociedade começa com a chamada Geração de 1870 e particularmente com Sílvio Romero, quando a busca por uma ontologia da nacionalidade no povo e em suas práticas e valores promove a inversão ideal/real defendida por Marx. Isso se torna mais possível com a abolição da escravatura, em que formalmente todos passam a condição de cidadãos, mas é um processo que se vai preparando de longa data, em que, entre outros, tiveram grande importância muitas atrizes, cantoras e bailarinas europeias que se radicavam no Brasil e acabavam se tornando a ponta de lança de uma mescla de culturas populares urbanas e a chamada "grande arte", que elas traziam de seu continente.

Se Romero fala de uma nação mestiça, ainda que buscando superá-la pelo branqueamento, e Gilberto Freyre vem para consagrar na análise sócio-histórica a celebração da mistura, algo aliás que também contou com uma longa história subterrânea nas culturas urbanas, parece-me ter sido Mário de Andrade quem, sobretudo a partir da literatura, mais profundamente elaborou a profunda mudança das sensibilidades que fez o Brasil se reconhecer como moderno. E desde então creio ser ainda pela via das artes que as interpretações se fizeram mais poderosas e influentes no imaginário social. Nós, 
cientistas sociais e historiadores não temos tido a mesma potência de um Guimarães Rosa, de uma Clarice Lispector ou de um Milton Hatoum. Talvez pela simples razão de que a linguagem das artes se legitima pela própria expressão das sensibilidades, enquanto que um conhecimento que se quer científico tem que enfrentar a espinhosa tarefa de falar sobre, de explicar o inefável. o que não deixa de ser a tarefa que temos.

Hoje, nas diversas áreas das humanidades, essa dificuldade tem sido enfrentada por estudos que se dedicam ao corpo, aos sentidos, às emoções, às sensibilidades, numa urgência ditada pela necessidade de entender uma realidade fluida e incongruente, em que grupos e povos se comportam na esfera pública movidos muitas vezes por seus sentimentos mais obscuros e violentos. Se as revoluções Americana e Francesa estabeleceram o horizonte de expectativas do mundo contemporâneo e 1848 expressa o grito - ao mesmo tempo de desilusão e de esperança - que a conquista da liberdade, da igualdade e da fraternidade é possível, isso se deveu a uma profunda crença na razão libertadora.

O maio de 1968, por seu lado, ficou marcado por um grito, mais que desiludido, desesperado e sobretudo ambíguo. A imaginação no poder pode significar: "a razão não nos basta"; ou pior, "a razão não nos salva". E, claro, tudo cabe na imaginação - do sonho do paraíso terrestre ao dos monstros de Goya. Talvez por isso, a reação de Marcuse diante dos jovens sublevados nas barricadas de Paris. Jürgen Habermas, último representante da Escola de Frankfurt, ainda buscou dar sequência à perspectiva emancipatória de Marcuse, na contramão do ceticismo dos dois grandes pensadores da teoria crítica, Theodor Adorno e Max Horkheimer. Mas esse último fim de século e a entrada do novo milênio parecem ter dado mais ouvidos às desconstruções, às relativizações, a um mundo marcado pelas incertezas, a um real que, se existe, nos escapa sempre. Sim, precisamos ir além da razão e entender o ser humano na complexidade das suas manifestações da consciência, seu serno-mundo. Mas a crítica da razão não pode ser uma defesa da desrazão.

\section{BIBLIOGRAFIA}

Além das referências bibliográficas a partir de citações incluídas neste texto, incluo aqui ao menos uma obra representativa de autores citados, apenas como uma indicação de onde algumas das ideias abordadas podem ser encontradas.

ADORNO, Theodor; HORKHEIMER, Max. Dialética do Esclarecimento. Jorge Zahar, Rio de Janeiro, 1984.

AGUIAR, Flávio. A comédia nacional no teatro de José de Alencar. Ática, São Paulo, 1984.

ALENCAR, José de. Teatro completo 1. Funarte, Rio de Janeiro, 1977.

ANDRADE, Mário de. Macunaíma, o herói sem nenhum caráter. Círculo do Livro, São Paulo, 1984.

ARIÈS, Phillippe. História social da infância e da família. LTC, Rio de Janeiro, 1981.

ARIÈS, Phillippe; DUBY, Georges (dir.). História da vida privada. 5 vol. Companhia de Bolso, São Paulo, 2009. 
BARTHES, Roland. Mitologias. $4^{a}$ ed. Difel, Rio de Janeiro, 2009.

BENJAMIN, Walter. Illuminations: Essays and Reflections. Schocken Books, New York, 1969.

CORBIN, Alain. Le miasme et la jonquille. Flammarion, Paris, 1982.

Les cloches de la terre. Albin Michel, Paris, 1994.

DERRIDA, Jacques. A escritura e a diferença. Perspectiva, São Paulo, 1971.

DURKHEIM, Émile. As formas elementares da vida religiosa. Martins Fontes, São Paulo, 1996.

ELIAS, Norbert. 0 processo civilizador: uma história dos costumes. Zahar, Rio de Janeiro, 1990.

FEBVRE, Lucien. Honra e pátria. Civilização Brasileira, Rio de Janeiro, 1998.

FOUCAULT, Michel. Vigiar e punir. Vozes, Petrópolis, 1983.

FREYRE, Gilberto. Casa grande \& senzala. Record, Rio de Janeiro, 1998.

GOLDMANN, Lucien. Pour une sociologie du roman, Gallimard, Paris, 1964.

GUIMARÃES ROSA, João. Grande sertão: veredas. 3a ed. José Olympio, Rio de Janeiro, 1963.

HABERMAS, Jürgen. Mudança estrutural da esfera pública. Tempo Brasileiro, Rio de Janeiro, 1984.

HATOUM, Milton. Relato de um certo Oriente. Cia. das Letras, São Paulo, 1989.

HEGEL, Georg Wilhelm Friedrich. Princípios da filosofia do direito. Martins Fontes, São Paulo, 1997.

HUIZINGA, Johan. O outono da Idade Média. Cosac \& Naify, São Paulo, 2013.

LISPECTOR, Clarice. A hora da estrela. Rocco, Rio de Janeiro, 1998.

MARCUSE, Herbert. Eros e civilização. Zahar, Rio de Janeiro, 1968.

MARX, Karl. Contribution à la critique de l'économie politique. Éditions sociales, Paris, 1972.

MARX, Karl; ENGELS, Friedrich. A ideologia alemã. 2 v. Presença/Martins Fontes, Lisboa/São Paulo, 1973.

MAUSS, Marcel. Ensaio sobre a dádiva. In Sociologia e antropologia. Cosac \& Naify, 2003.

NABUCO, Joaquim. Minha formação. Editora Três, Rio de Janeiro, 1974.

PESAVENTO, Sandra Jatahy. Sensibilidades: escrita e leitura da alma. In PESAVENTO, S.; LANGUE, Frédérique (orgs.). Sensibilidades na história: memórias singulares e identidades sociais. Ed. da UFRGS, Porto Alegre, 2007, p. 9-21.

ROMERO, Sílvio. Contos populares do Brasil. Armazém da Cultura, Fortaleza, 2013.

SIMMEL, Georg. On Individuality and Social Forms. Donald N. Levine (ed.). The University of Chicago Press, Chicago, 1971.

. As grandes cidades e a vida do espírito. Mana. Estudos de antropologia social, Rio de Janeiro, n. 11, v. 2, 2005, p. 577-591.

WEBER, Max. A ética protestante e o "espírito" do capitalismo. Cia. das Letras, São Paulo, 2004.

\section{NOTAS DE FIM}

1. Título da gravura de $n^{\circ} 43$ da série de 80 estampas intitulada Caprichos, de Francisco Goya, publicada em 1799. 
2. "Luz, mais luz". Supostas últimas palavras de Johann Wolfgang von Goethe em seu leito de morte, em 1832.

3. Depoimento que me foi dado pelo próprio Leenhardt, a quem agradeço a autorização para utilizá-lo neste texto.

4. Apesar de a formulação ser bem conhecida, vale a pena reproduzir um trecho maior da citação, que esclarece o pensamento de Marx: [Na] produção social da sua existência, os homens entram em relações determinadas, necessárias $e$ independentes da sua vontade, relações de produção que correspondem a um grau de desenvolvimento determinado das suas forças produtivas materiais. O conjunto dessas relações de produção constitui a estrutura econômica da sociedade, a base concreta sobre a qual se eleva uma superestrutura jurídica e política e à qual correspondem formas de consciência sociais determinadas. Não é a consciência dos homens que determina o seu ser; mas inversamente é o seu ser social que determina a sua consciência (MARX, 1972: p. 4).

5. Aguiar define o "outro" interno da sociedade brasileira oitocentista (o terceiro na série de alteridades que ele propõe) como sendo "o triste legado colonial", traduzido pela "tacanhice provinciana". Ainda que o autor coloque a escravidão no centro deste "outro", isso me parece insuficiente, pois abolida esta e modernizado o país o terceiro "outro" desapareceria. No entanto, o que vamos constatar na história que se segue é que o terceiro "outro" continua a assombrar a sociedade brasileira, definido a partir das difíceis relações interétnicas e em particular da problemática absorção da população afro-brasileira e do legado cultural africano.

\section{RESUMOS}

A relação entre ser e consciência é um problema que atravessa a história da filosofia e funda as ciências sociais. Como resultado dos embates entre perspectivas idealistas e materialistas, firmase uma convicção da importância de se ir além do dualismo e do determinismo: os seres humanos vivendo em sociedade em seu devir histórico estão imersos em sua cultura, suas representações, seus valores, ao mesmo tempo em que atuam sobre e modificam sua realidade. Outro par binário então se apresenta como desafio para as questões de consciência: razão e emoção. Este breve ensaio procura refletir - a partir de dois anos icônicos na história ocidental, 1848 e 1968 - como tais questões vêm se impondo ao pensamento social e à historiografia contemporânea.

La relation entre l'être et la conscience est un problème qui traverse l'histoire de la philosophie et fonde les sciences sociales. À la suite des affrontements entre perspectives idéalistes et matérialistes, s'est établie la conviction de l'importance de dépasser le dualisme et le déterminisme. Les êtres humains vivant en société dans leur développement historique sont immergés dans leur culture, leurs représentations, leurs valeurs, en même temps qu'ils agissent sur et modifient leur réalité. Un autre couple binaire se présente alors comme un défi aux problèmes de conscience : raison et émotion. Ce bref essai cherche à réfléchir - à partir de deux années emblématiques de l'histoire occidentale - 1848 et 1968 - sur la question de savoir comment de telles questions s'imposent à la pensée sociale et historique contemporaine.

\section{ÍNDICE}

Mots-clés: être; conscience; raison; sensibilité; émotion; pensée

Palavras-chave: ser; consciência; razão; sensibilidade; emoção; pensamento 
AUTOR

ANTONIO HERCULANO LOPES

Fundação Casa de Rui Barbosa - Rio de Janeiro, Brasil História cultural

herculano@rb.gov.br 